lifestyle, many are reluctant to return. These issues were discussed at length at the recently held South Asian Federation of Psychiatric Association's Annual Academic Sessions in Kalutara, Sri Lanka.

We believe that there are a few options to reduce this crisis, for instance enhancing the recruitment of more doctors into psychiatry or improving the knowledge of psychiatry among primary care doctors. Already some medical schools in Sri Lanka (e.g. University of Kelaniya and University of Colombo) have addressed this issue and increased the psychiatry training component in their undergraduate curricula. One of them is Colombo Medical School where psychiatry is assessed as a separate subject in the final Bachelor of Medicine and Bachelor of Surgery (MBBS) examination. Soon psychiatry will be incorporated as a separate subject at the final year assessment at the Faculty of Medicine, University of Kelaniya.

The importance of improving the quality of undergraduate teaching in order to enhance the recruitment of medical graduates to the field of psychiatry has been emphasised (Sierles et al, 2003). When medical students are more knowledgeable, fear and stigma associated with psychiatry, which seems to be more prevalent in low-income countries such as Sri Lanka, become less prominent.

A recent survey carried out among undergraduates in medical schools in the Western Province of Sri Lanka demonstrated that the career choice in psychiatry is about $2 \%$, which is less than in the Western world (details are available from the author). A study in Spain has shown that the career choice for psychiatry was $6 \%$, compared with $4.5 \%$ in the USA (Pailhez et al, 2005).

Psychiatry seems to be a less attractive medical field globally. Overworked psychiatrists with minimum rewards for their work tend to lose their interest in the profession, which can adversely influence the quality of care and teaching. Psychiatrists should be aware of factors that will help them prevent that.

As medical teachers and practising psychiatrists we should also be aware of the problems encountered in psychiatry to enhance the recruitment and retention of psychiatrists.

SIERLES, F. S., YAGER, J. \& WEISSMAN, S. H. (2003) Recruitment of US medical graduates into psychiatry: reasons for optimism, sources of concern. Academic Psychiatry, 27, 252-259.

PAlLHEZ, G, BULBENA, A. \& BALON, R. (2005) Attitudes to psychiatry: a comparison of Spanish and US medical students. International Psychiatry, 10 $6-8$

K. A. L. A. Kuruppuarachchi Professor of Psychiatry, Faculty of Medicine, University of Kelaniya, PO Box 6, Thalagolla Road, Ragama, Sri Lanka, email: alithkuruppu@|ycos.com

doi: 10.1192/pb.32.4.154b

\section{New Ways of Working: implications for patients in adult psychiatry}

We read with interest the article by Mehta et al (Psychiatric Bulletin, December 2007, 31, 381-384). Community mental health teams' case-loads comprise a variety of service users such as stable patients requiring 'routine followups', long-term patients caught in the system, 'revolving door' patients (who tend to slip through the net), patients requiring social care and newly referred individuals. There is a tendency for the 'status quo' service users on standard Care Programme Approach to remain in the mental health system for routine outpatients.

It is difficult to define a 'complex patient' as their and the carer's opinions may differ from the objective. However, we think the authors' parameter of defining a 'complex patient' based on time elapsed since the last appointment, level of Care Programme Approach and lack of objective clinical activity are a good measure of complexity.

The New Ways of Working emphasises the role of a consultant psychiatrist in complex cases. However, after more than 2 years from its introduction the actual initiative is still patchily distributed within organisations and all its main principles are not fully accepted. We agree with the authors that once the New Ways of Working is implemented, routine followups would be expected to be eliminated from consultant's care.

The consultants and the multidisciplinary teams should change the current practice, laying more emphasis on the brief short-term interventions, promoting recovery, self-dependence and timely discharge to primary care. Stable patients can be effectively managed in primary care and an initiative to improve liaison with general practitioners can facilitate such people to be followed-up.

However, it would be interesting to see how the new breed of consultants who start their career under New Ways of Working would function in the long-term. In trying to use the skills of a consultant psychiatrist more effectively to deliver their expertise more 'timely' than 'routinely', there is a danger that they may end up in dealing with 'complex patients' only. Consultants may also lose the skills to manage 'routine patients', who are far more common than 'complex patients' in a psychiatric practice.

*Arvind Sharma Consultant Psychiatrists and Medical Lead, Holly Lodge Community Mental Health Team, 45 Church Lane, Cheshunt, Hertfordshire EN8 ODR,email: arvind.sharma@hertspartsft. nhs.uk, Venkat Raj Goud Kondan Locum Consultant, Community Mental HealthTeam Ware, Hertfordshire Partnership Foundation Trust,
Hertfordshire, Ayesha Naveed Specialty Registrar Year 2, Community Mental HealthTeam Cheshunt, Hertfordshire Partnership Foundation Trust, Hertfordshire

\section{Child and adolescent in-patient units - room for expansion}

We read with interest the concerns expressed in a recent article by Cotgrove et al (Psychiatric Bulletin, December 2007, 31, 457-459). The Ashfield Unit is an adolescent unit able to accept emergency admissions that opened in 2003 in recognition of a lack of emergency provision leading to delayed admissions and inappropriate use of paediatric or adult psychiatric wards. Our experience since opening has been in contrast to the concerns expressed by Cotgrove et al. We have not had inappropriate admissions and there have been no difficulties with recruitment and retention of staff.

What has been unexpected is the high level of violence, aggression and risk to others in some young people. This may be similar to the experience in adult psychiatry in recent years, with only the most disturbed patients being referred for admission into in-patient psychiatric units. There has been a higher than expected need for intensive nursing care in a lowstimulus environment - a third of our young people presenting with psychosis required the use of the intensive nursing area at some point in their admission (Cullen et al, 2006).

Although O'Herlihy et al in their paper (2007) demonstrate a dramatic increase in forensic provision, we would recommend an increase in provision of a spectrum of psychiatric intensive care units for adolescents alongside general and acute adolescent in-patient units, which could be used flexibly to allow the young person to be rehabilitated back onto an open ward as soon as possible.

CULLEN, L.,THOMAS, B. \& SMITH, P. (2006) A novel acute admission and assessment service for teenagers with first episode psychosis. Schizophrenia Research, 86 (supp 1), $\mathbf{5 1 6 8 .}$

O' HERLIHY, A., LELLIOTT, P, BANNISTER, D., et al (2007) Provision of child and adolescent mental health in-patient services in England between 1999 and 2006. Psychiatric Bulletin, 31, 454-456.

*Nicole Karen Fung Specialist Registrar in Child and Adolescent Psychiatry, Ashfield Unit, Parkview Clinic, 60 Queensbridge Road, Moseley, Birmingham B138QE, email:nkf@doctors.org.uk, Linda Cullen Consultant Child and Adolescent Psychiatrist, Ashfield Unit

doi: $10.1192 / p b .32 .4 .155 a$ 